\title{
Correction to: Characterization of biomarkers in stroke based on ego-networks and pathways
}

\author{
Haixia Li • Qian Guo
}

Published online: 21 July 2018

(C) Springer Nature B.V. 2018

Correction to: Biotechnol Lett (2017) 39:1835-1842

https://doi.org/10.1007/s10529-017-2430-2

In the original publication of the article, the second author name was published incorrectly. The corrected author name is given in this correction.

The original article can be found online at https:// doi.org/10.1007/s10529-017-2430-2.

H. Li ( $)$ - Q. Guo

Department of Neurology, The 2nd People's Hospital of Liaocheng, 306 Jiankang Road, Linqing,

Liaocheng 252600, Shandong Province, People's

Republic of China

e-mail: lilin5231@163.com 